\title{
Socialification: Social Software Elements Analysis and Design
}

\author{
Reem Ayouby \\ John Molson School of Business \\ Concordia University \\ Reem.Ayouby@concordia.ca
}

\begin{abstract}
The goal of this paper is to initiate a conversation on the undergraduate teaching of social software analysis and design in applications which are nonsocial-media specific. This course covers the topics required to strategically "socialify" organizational applications to engage users in the most productive way for the organization. To capture this effort, we suggest the term "socialification" which means the use of social software design features in non-socialmedia applications. We provide some background and course goals and learning objectives as well as a course structure. We then discuss issues to consider when implementing a course in social software elements development. We also cover the theoretical grounding related to the interdisciplinary process and explain how it contributes to the design of the course.
\end{abstract}

\section{Introduction}

The last decade has seen explosive rates of social media diffusion. For example, Facebook accounts became available to the public on the $26^{\text {th }}$ of September 2006. On average, during March 2018, there were 1.45 billion daily active users [14].

Research on the reasons behind widespread acceptance suggests that social media activates both the conscious and non-conscious motivational systems to create use $[2,3,28,59]$. By tapping into the most recent theorizing and empirical research related to the motivational value of social software design, we propose a course outline as a starting point to a discussion on leveraging what is currently known about social media.

A course on this timely topic is likely to garner significant interest from the undergraduate student community. Additionally, the social software phenomenon has proven that it is not a passing fad and thus the timing for this course is appropriate.

Courses addressing this topic are needed because although social media such as Facebook offer many advantages, they also have limitations in terms of data

\author{
Anne-Marie Croteau \\ John Molson School of Business \\ Concordia University \\ Anne-Marie.Croteau@concordia.ca
}

privacy and intellectual property protection. This has recently been reflected in the case of Cambridge Analytica [9] and others [43]. Although governmental organizations are updating privacy laws with regulations such as the General Data Protection Regulation (GDPR) by the European Union [12], it is too soon to know the extent to which these regulations will be effective.

Thus, organizations looking for the collaboration advantages offered by social media may not find the terms of service of proprietary social media platforms favorable. Yet, theoretical and empirical research on social media has now reached a critical point which would allow for universities to transfer knowledge to undergraduate students such that the next generation of graduates will be able to develop software features that will provide the social functionality of proprietary platforms within the secure and controlled infrastructure of organizational systems.

\section{Contextual Background}

For clarity, some definitions may be helpful. Social media is a composite of Web 2.0 technologies integrated to facilitate interpersonal communication and collaboration through the creation and sharing of content by users $[26,27,30]$. A platform is an electronic infrastructure on which applications are built [19]. Social media platforms are electronic infrastructures on which social media applications are built to facilitate the end user's content creation and sharing by providing the technological structures that eliminate any need to write computer programs or scripts. The most common forms of social media applications are now based on platforms and although platforms exchange information seamlessly, they are nevertheless organized with clear boundaries.

For example, a video clip may be shared on Facebook but remain on the original social media site (e.g. YouTube). This makes it subject to the user agreement that is specified by the host platform. Additionally, most of these social media platforms are made available to end users free of charge but supported by an advertising based business model [52] 
which will naturally prioritize revenue generating activity needs over the needs of non-paying users. However, now that users have a social media culture, the need for socially enabled software in organizational or non-proprietary contexts is developing [25].

If we consider the case of the open source learning management systems (LMS) Moodle, we can see that multiple pluggable companion components are being developed to fill the need generated for social software support-for example, Mahara [46]. As the interest in social software increases, the need for specialized training also emerges.

In this paper, we focus this proposed course on equipping students with the interdisciplinary knowledge-base needed to socialify applications by infusing them with social software elements. A social software element is a software object which implements social media functionality in a non-social media specific application to support social interaction in appropriate situations by authorized system users.

Consistent with Kane [25], we believe that the future of social software lies in the mindful integration of these social software elements within organizational systems where social needs are relevant and can have a positive impact [42].

\subsection{Socialification}

This course is designed to give students an understanding of various factors that intersect in what we call the socialification of software systems. The term is composed of the root word 'social' and the suffix '-ification'. 'Social', in the current context, is defined as "relating to online technologies, activities, etc., that promote companionship or communication with friends and other personal contacts: social websites such as Facebook; the use of social software to share expertise" [11]. The suffix '-ification' refers to the process of becoming [61]. Thus, socialification is the use of social software design features in nonsocial media specific applications to make them more social. We are suggesting this 'socialification' term to facilitate a more efficient discussion of related concepts and processes.

The proposed course structure addresses the three domains of socialification and their integration (see Figure 1). These are social software functionality, individual social needs, and organizational (or other target domain goals).

Individual social needs are a key criterion because they are the least accessible to software developers using traditional approaches. There are factors which are implicit that are impossible to elicit during the needs analysis phase of software development.
However, motive disposition theory and its associated research methods provide guidance for the discovery of implicit factors such as implicit motives. This course aims to explicitly train students to account for the inclusion of implicit factors during the development of software functions and features.

Socialification can be done for various reasons: To increase the system users' engagement with the software application, to enhance knowledge sharing, or to enhance the social connections among employees for various secondary benefits such as increased cooperation, integration, and innovation.

According to Kane [25], social features embedded in organizational systems will have a more important impact for organizations than the stand-alone proprietary solutions. Further, most organizations would not want to have their information hosted on proprietary and publicly accessible social platforms. The course explores these issues and how they can be overcome by planning and implementing social functions and features right into the organizational software by means of social software elements.

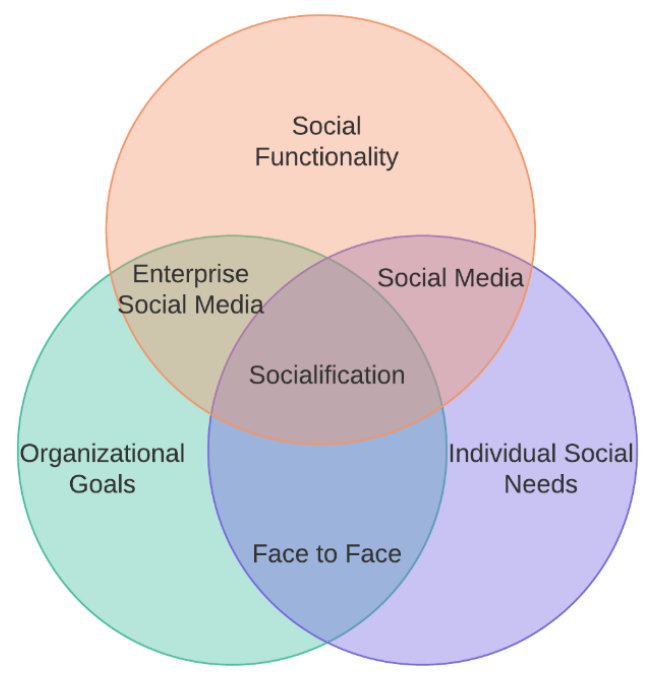

Figure 1: Domains of Socialification

\subsection{Need for a Socialification Course}

The multidisciplinary nature of social software development renders the offering of undergraduate university courses somewhat challenging [34]. As stated in the calls for papers in this HICSS-52 invited track on software engineering education and training, the educational offerings are frequently advanced through the development of reference syllabi on the academic side and practitioner initiatives focused on industry-based trainings on the professional side. In the rapidly evolving sphere of software development, 
integrating the results of research into the undergraduate curriculum is a necessary challenge. In this paper, we address this challenge by suggesting a starting point to initiate the conversation around what would be needed to advance an undergraduate course in social software element analysis, design, and implementation.

A review of educational Information Systems (IS) programs shows that there is a significant level of interest in social media [7]. However, thus far, the focus of this interest has been related to two main areas: firstly, the marketing and communication uses of the existing social media applications; and secondly, the use of social media as a source of big data for analytics. The academic programs mentioning the development of social software elements are limited to one program which clearly identified this as a goal: "The composed courses cover all fields related to the development of social-technical artefacts: This includes the areas of social psychology, design, informatics, media and business administration." [7:286]. This is offered at the University of Siegen as part of their Master of Science in Human-Computer Interaction. Outside of the programs listed in the AIS education report mentioned above, other universities appear to be offering a limited number of courses but only at graduate levels.

Although there may be other courses on offer which overlap in content with the course we are proposing here, these programs addressing this need are master's level programs [60], which leaves the undergraduate educational area currently unaddressed.

Beyond university courses, Coursera offers a social computing 3 week course [33] taught by the University of California at San Diego. Within industry, some specialized training courses are starting to emerge such as the one on Coursera. In spite of that, there is a call for more such courses from the user experience (UX) community [44].

However, there remains missing a discussion within the reference curricula about the addition of undergraduate courses serving the social software need. We hope this paper contributes towards development on the course design for an undergraduate course.

\section{Proposed Course}

This proposed course gives students the tools to leverage social elements for organizational information systems by:

A. analyzing the social functions and features of social media platforms,

B. outlining relevant organizational goals, individual social needs and their intersection (as in Figure 1),
C. evaluating the fit between functions and features with the social and organizational needs they support,

D. identifying organizational application systems which are suitable for the inclusion of social software elements,

E. transferring these social functions and features to organizational applications which do not have social functions, and

F. demonstrating the analysis and design of a set of functions and features that enhance an existing organizational platform (e.g. Moodle).

\subsection{Learning Objectives}

During the course, students will develop the competencies to:

a) Identify social functionality and explain the various social functional elements which implement them.

b) Identify the features which pull on the nonconscious motives and their expected effects on the users' interaction with the system.

c) Articulate the differences between a feature's verbal and visual characteristics.

d) Explain the criteria for choosing between verbal and visual design characteristics when designing a social software element.

e) Apply understanding of social functionality and its supporting features in the socialification of organizational information systems.

f) Suggest and justify social functions and features by discussing the correspondence with individual social needs and organizational goals.

g) Analyze the social needs of individuals, goals of organizations, and the needed supporting social software elements.

h) Create and justify a socialification plan for an organizational information systems platform.

i) Design, develop, implement, and test the planned socialification elements.

j) Demonstrate the above through documentation including diagrams and textual explanations; presentations; mock screens; working opensource and version-controlled software modules.

\subsection{Topic Description and Assessment}

This section describes the main topics and the various methods of assessing student learning. The organization follows a 13-week semester (W01-W13). The course takes an active learning approach with frequent activities, associated deliverables and feedback. Individual assessment includes two quizzes 
of $20 \%$ each; a written reflection on socialification, interdisciplinary group work, and student's own contributions (10\%); and ongoing participation in Moodle forum discussions (10\%). The group work $(40 \%)$ includes a prototype with milestones that include a project proposal, plan, documentation, mock-ups, presentation and demo.

W01 - Social media in general includes the introduction to the course content and functioning happens in the first class and includes an overview of public, proprietary social media platforms such as Facebook, LinkedIn, and YouTube. Students are introduced to criteria to help them understand the similarities and differences between these platforms from a functional (purpose served by the platform) and feature (technical elements used to implement the functionality) based perspective. The applicability of design thinking is also discussed to raise students' awareness on the methods which may be used while developing software in the context of social software elements. This introduction also includes a brief discussion of project planning and the logic for experiential project-based group work. Readings: [27, 30, 31], [49]; Due: Group formation.

W02 - Socialification part 1: Social software analysis: Firstly, the focus will be on the main functionality and features of social software elements. This discussion includes user experience design in the context of social software. Reading: Handout based on [4]. Secondly, the types of software features which implement these social functionalities. Readings: Handout, [24:51 Section 5.1], [1, 10, 63].

W03 - Social media in organizations This topic addresses organizational social media. For example, Enterprise Social Media: current focus and uses, their functions and features, and challenges. Readings: [38, 39, 40, 41, 50]. Due: Group project proposal (5\%)

W04 - Individual social needs This topic provides an exploration of social needs via self-determination theory and motive disposition theory (explicit and implicit motives). This topic emphasizes the importance of considering individual needs, the contrast between conscious and non-conscious motives, and how they affect a user's interaction with an application. Although a significant portion is related to the interface, functionality is also a significant consideration. Readings: $[17,54]$.

W05 - Organizationally focused goals This topic provides an overview of the goals which are relevant to the organization and the interaction between organization level goals and individual level factors. Reading [16].

W06 - Traditional and modern organizational software This topic covers areas related to the implementation of the functions and features of social software elements. Examining infrastructure topics such as the need for a social identity server, microservice architectural requirements, and social software API standards for social software elements is necessary here. As an example, instructors may examine Moodle as an example of an organizational software that is domain focused on education. Readings: [6, 8, 18, 21, 53, 55, 56, 58, 62]. Due: Quiz $1(20 \%)$ during first half of class for topics from W01 to W05.

W07 - The fit between social software, individual social needs, and organizational goals. This area of overlap is where the opportunity lies for the impact that would be possible through the design of social software features. A key competency in this area would be the successful alignment of the three overlapping areas to produce a functional social software element. Readings: [2, 16, 22, 28, 63]. Due: Group project description of proposed features (5\%)

W08 - Socialification part 2: Creating social software elements This topic's focus is identifying the potential for social features in traditional organizational software applications such as ERPs; social functional needs analysis details; mapping social functionality to social features of software. Readings: Developing corresponding use-cases [29].

W09 - Socialification examples The goal of this topic is to discuss emerging non-social media specific applications which include social software elements and the companies which are making the software elements that support and use them including Freshworks Chat, [15] for social software elements, Once a Month Meals_-a Socialified service and is Expedia seeking socialification through the purchase of Trover and Alice $[13,45,64]$ ?

W10 - Socialification success factors integrates the alignment between the three socialification domains and the success of the social software element [42], and also considers the issue of where and when to include a social software element becomes relevant. Can this decision be delegated to an AI engine? How would that be done? Readings: [42, 57]. Due: Group project of proposed mock-ups (5\%).

W11 - Special issues in designing and implementing social software elements: User privacy regulations in general and in special contexts; Supporting IT decision makers on criteria to consider when making social element choices for their future systems; Providing policy guidelines in addition to decision making tools; Contextual elements to consider when adding social software elements to systems; and Cultural issues in the design of social software elements. Readings: [12, 20, 23]. Due: Quiz $2(20 \%)$ during first half of class for topics from W06 to W10. 
W12 - Testing social software and the ideas which were generated through the integration of concepts. More specifically, students will test and demonstrate their social software elements. Reading: [51] Due: Written reflection on the learning experience (10\%)

W13 - Demo presentations This last lecture is entirely reserved to the group projects presentations. Due: Presentations (5\%) and assessment of the group projects (final product and documentation (20\%)).

\subsection{Situating the Course Within an Undergraduate Program}

This is an interdisciplinary course at the intersection of information systems, psychology, and software engineering. The information systems component contributes the organizational knowledge from the business school perspective. The psychology component contributes the understanding of both conscious and non-conscious individual social needs. Finally, the software engineering component contributes the programing and architectural component to implement the social software functionality.

Lattuca et al. [37] found that making interdisciplinary courses open to students from the various reference disciplines increases the students' resulting interdisciplinary competence. Therefore, this course is conceived as an advanced course which may be offered to senior students of the three reference disciplines, namely: information systems, psychology, and software engineering. Each senior student is then assumed to have achieved a satisfactory level of competence in their own discipline, thus reducing the burden of learning about three new disciplines to two disciplines.

Software engineering and information systems students are expected to be well versed in the use of systems analysis and design principles, UML, and preferably object-oriented Internet programming. A background in user experience (UX) and User Interface (UI) design is an advantage. For the psychology students, course work in cyberpsychology would be a very helpful advantage.

Skills in managing projects and teams are necessary for the course activities. Students need to have a strong interest in all the reference disciplines. Although not an explicitly stated reference discipline, an interest in art and a facility with artistic terminology would be an advantage to students due to the discussions on the visual components of social software.

\section{Theoretical Grounding: Interdisciplinary Education Theory}

As is becoming clear from the discussion thus far, the socialification space requires knowledge from multiple disciplines. Taking a multidisciplinary approach would indicate that the knowledge needed could be used in an additive manner by concatenating the relevant portions. However, for more innovation, an integrative approach which would allow for the emergence of new knowledge at the boundary of the disciplines is referred to as an interdisciplinary approach [36]. More precisely, it is defined as: "a process of answering a question, solving a problem, or addressing a topic that is too broad or complex to be dealt with adequately by a single discipline or profession . . . and draws upon disciplinary perspectives and integrates their insights through construction of a more comprehensive perspective" [32:393]

By its nature, social software includes both the social and the engineered. Therefore, to learn how to create software which is social, an integration of social science disciplines with software engineering is needed. However, along with the advantages which are presented by interdisciplinary education, the approach also poses some challenges. For example, the perspectives of the various disciplines which are included also mean differences between their approaches, methods, and priorities. This is particularly true for the engineering and social sciences where such differences also affect the concepts and associated terminologies. Therefore, to provide a supportive structure for the course development, delivery, and evaluation process we are undertaking here, we draw on the interdisciplinary education field for the educational theoretical grounding.

This interdisciplinary grounding is intended to mitigate and leverage disciplinary differences which are due to theoretical and cultural aspects that become reflected in disciplines' education, training, and accumulating experience [5]. By following the process proposed by Newell [48], a deeper understanding will result for all course participants through not only developing common ground, but also knowledge integration.

The steps in the process are divided into two general phases. The first is based on drawing on disciplinary perspectives and consists of six steps and the second is based on integrating their insights and consists of eight steps. Newell emphasizes that these steps overlap, are iterative and heuristic in nature and that integration is a continuous process. Nevertheless, 
the articulation of an organized set of phases and steps provides guidance, particularly in the case of an undergraduate interdisciplinary course.

\subsection{Theoretical Grounding}

In this paper, we set out to suggest a new course. We ground the course design in the interdisciplinary education literature by borrowing from Newell's 2007 interdisciplinary process to help structure the course. We suggest that a theoretically grounded method would create a well-structured interdisciplinary course mitigating some of the risks of offering such a course to a diverse audience. Please see Figure 2 and Table 1 which illustrates how the process is reflected in the course structure in a non-linear manner to respect the logical structure of the socialification approach. Table 1 links the Newell's steps with the learning outcomes and refers to the weeks during which these are addressed.

For the following section, we focus the discussion on the alignment between the interdisciplinary education process and the socialification course design.

\subsection{The Interdisciplinary Process}

Newell proposed a two phased approach to the interdisciplinary process [48:248] as illustrated in Figure 2. It consists of six steps in the first phase and 8 steps in the second phase. The process starts with a purely multidisciplinary approach whereby each relevant discipline is studied independently and used to examine the problem from the discipline's unique perspective. This can be thought of as the scaffolding for the next phase [35, 36].

During this first phase, teaching focuses on defining the issue of socialification and explaining the three disciplines so students can learn how to better understand the goals of the organization that would need social software elements, document its requirements and try to capture the individual social needs of the employees in context. The technical infrastructure and software implementation issues would also be considered in this phase. Considering the three domains of socialification separately is consistent with Newell's approach in phase I. (See the upper part of Figure 2)

The second phase takes a highly integrative approach. The 8 steps facilitate the synthesis and integration of the various disciplinary perspectives. The techniques include identifying inconsistencies in thinking and misalignment of assumptions, then working to create common ground that connect and facilitate the emergence of new insights. This is where the three domains overlap to socialify software and better integrate the observations made regarding the needs, potential conflicts, and common ground that would be needed to develop a software that is socially enhancing because it reflects the individual social needs through mindfulness of social functionality and organizational goals (See the lower part of Figure 2). This phase is productive because the integration process results in the creation of new knowledge and/or artifacts.

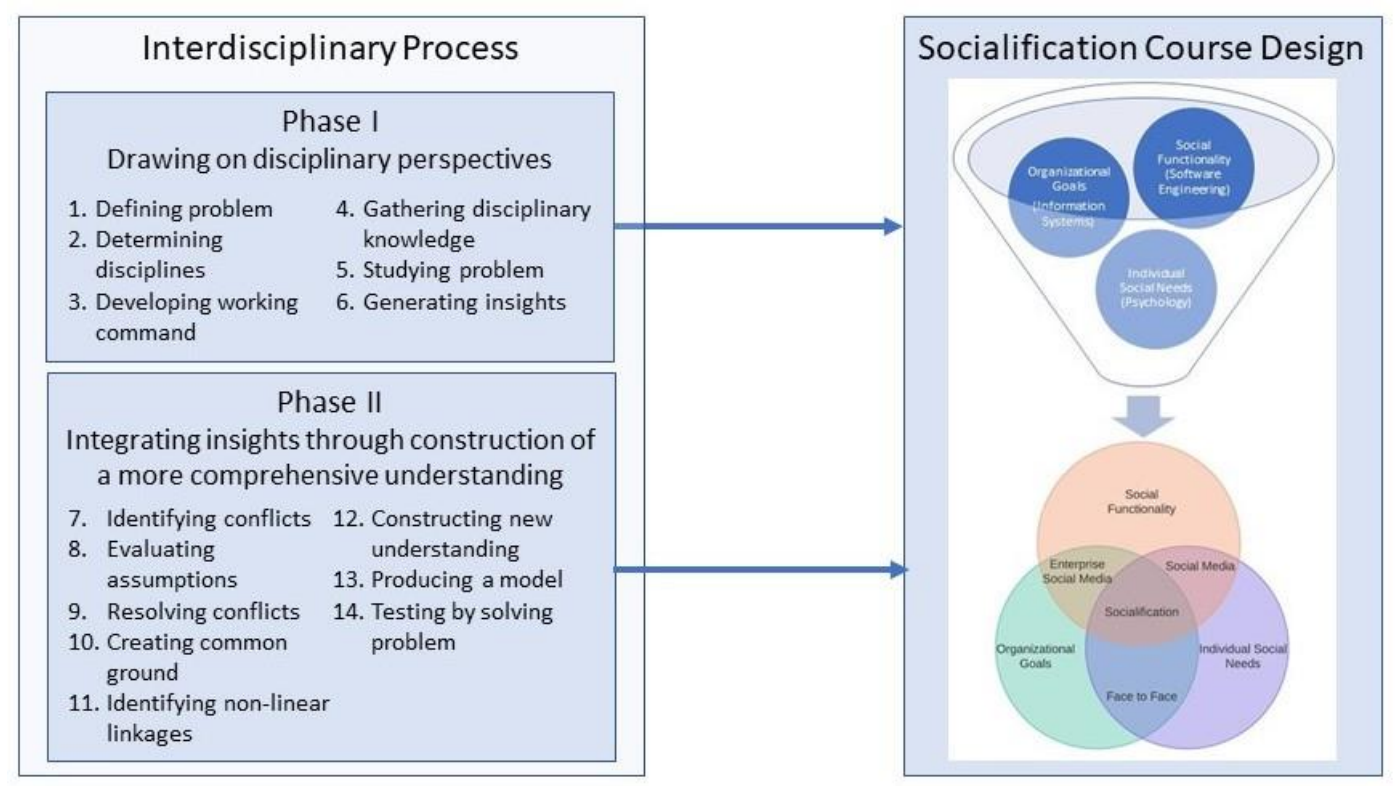

Figure 2: Theoretical Grounding 
Table 1: Interdisciplinary Education Method and Course Content Alignment

\begin{tabular}{|c|c|c|c|}
\hline \multicolumn{2}{|r|}{$\begin{array}{l}\text { Newell's [48:248] Steps } \\
\text { (short descriptions) }\end{array}$} & $\begin{array}{l}\text { Course Alignment Examples where the Capital letter refers to course goals } \\
\text { whereas small letter to the course objectives }\end{array}$ & Status and topic \\
\hline \multirow{6}{*}{ 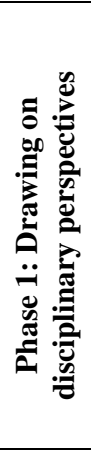 } & $\begin{array}{l}\text { 1. Defining the problem (question, } \\
\text { topic, issue) }\end{array}$ & $\begin{array}{l}\text { The socialification-the mindful infusing of social software elements } \\
\text { into non-social media applications. }\end{array}$ & \multirow{2}{*}{$\begin{array}{l}\text { - Social media in general (week 1) } \\
\text { - Socialification part 1: Social software analysis: } \\
\text { functionality and features (week 2). } \\
\text { Figure 1: Domain of Socialification }\end{array}$} \\
\hline & 2. Determining relevant disciplines & $\begin{array}{l}\text { Determined by the course design, but contextual in nature and may } \\
\text { need to expand to include other disciplines. }\end{array}$ & \\
\hline & $\begin{array}{l}\text { 3. Developing a working command } \\
\text { of the relevant disciplines. }\end{array}$ & $\begin{array}{l}\text { a) Identify social functionality and explain the various social functional } \\
\text { elements which implement them. }\end{array}$ & \multirow{3}{*}{$\begin{array}{l}\text { - Individual social needs (week 4) } \\
\text { - Organizationally focused goals (week 5) } \\
\text { - Traditional and modern organizational } \\
\text { software (week 6) }\end{array}$} \\
\hline & $\begin{array}{l}\text { 4. } \begin{array}{l}\text { Gathering all relevant } \\
\text { disciplinary knowledge }\end{array} \\
\end{array}$ & Supported by course design and assigned student work. & \\
\hline & $\begin{array}{l}\text { 5. Studying the problem from the } \\
\text { perspective of each discipline }\end{array}$ & $\begin{array}{l}\text { g) Analyze the social needs of individuals, goals of organizations, and } \\
\text { the needed supporting social software elements. }\end{array}$ & \\
\hline & $\begin{array}{l}\text { 6. Generating disciplinary insights } \\
\text { into the problem }\end{array}$ & $\begin{array}{l}\text { g) Analyze the social needs of individuals, goals of organizations, and } \\
\text { the needed supporting social software elements. }\end{array}$ & $\begin{array}{l}\text { - The fit between social software, individual } \\
\text { social needs, and organizational goals. (week 7) }\end{array}$ \\
\hline \multirow{8}{*}{ 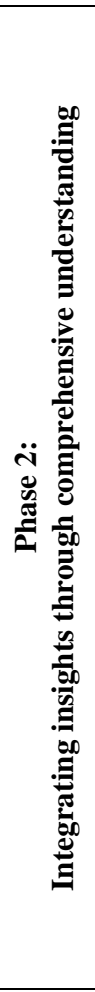 } & 7. Identifying conflicts in insights & $\begin{array}{l}\text { c) Articulate the differences between a feature's verbal and visual } \\
\text { characteristics. } \\
\text { g) Analyze the social needs of individuals, goals of organizations, and } \\
\text { the needed supporting social software elements. }\end{array}$ & $\begin{array}{l}\text { - The fit between social software, individual } \\
\text { social needs, and organizational goals. (week 7) } \\
\text { - These will be additionally addressed through } \\
\text { the experiential course activities. }\end{array}$ \\
\hline & $\begin{array}{l}\text { 8. Evaluating assumptions and } \\
\text { concepts }\end{array}$ & $\begin{array}{l}\text { B. outlining relevant organizational goals, individual social needs and } \\
\text { their intersection (as in Figure 1) } \\
\text { c) Articulate the differences between a feature's verbal and visual } \\
\text { characteristics. }\end{array}$ & $\begin{array}{l}\text { Some tensions also appear within a topic as in } \\
\text { explicit vs. implicit motives and more traditional } \\
\text { vs. modern software design or project management. } \\
\text { - Socialification part } 2 \text { (week } 8 \text { ) }\end{array}$ \\
\hline & Resolving conflicts & $\begin{array}{l}\text { Resolving conflicts would be learned though working on course } \\
\text { assignments which would ideally include real world examples, have } \\
\text { relevance, and an impact. }\end{array}$ & $\begin{array}{l}\text { - Socialified applications: examples (week 9) } \\
\text { - Social software element success factors to } \\
\text { consider (week 10) }\end{array}$ \\
\hline & 10. Creating common ground & $\begin{array}{l}\text { f) Suggest social functions and features and justify these choices by } \\
\text { discussing the correspondence with individual social needs and } \\
\text { organizational goals. }\end{array}$ & $\begin{array}{l}\text { - The fit between social software, individual } \\
\text { social needs, and organizational goals. (week 7) }\end{array}$ \\
\hline & 11. Identifying (nonlinear) linkages & $\begin{array}{l}\text { b) Identify the features which pull on the non-conscious motives and } \\
\text { the expected effects of these features on the users' interaction with } \\
\text { the system. }\end{array}$ & $\begin{array}{l}\text { - The fit between social software, individual } \\
\text { social needs, and organizational goals. (week 7) }\end{array}$ \\
\hline & $\begin{array}{l}\text { 12. Constructing a new } \\
\text { understanding of the problem }\end{array}$ & $\begin{array}{l}\text { e) Apply understanding of social functionality and its supporting } \\
\text { features in the socialification of organizational information systems. } \\
\text { f) Suggest social functions and features and justify these choices by } \\
\text { discussing the correspondence with individual social needs and } \\
\text { organizational goals. }\end{array}$ & $\begin{array}{l}\text { - Social software element success factors to } \\
\text { consider (week 10) }\end{array}$ \\
\hline & $\begin{array}{l}\text { 13. Producing a model to capture } \\
\text { new understanding }\end{array}$ & $\begin{array}{l}\text { d) Explain the criteria for choosing between verbal and visual design } \\
\text { characteristics when designing a social software element. }\end{array}$ & $\begin{array}{l}\text { The course assessments, which include an } \\
\text { experiential project, are designed to assist students }\end{array}$ \\
\hline & $\begin{array}{l}\text { 14. Testing the understanding by } \\
\text { problem solving. }\end{array}$ & $\begin{array}{l}\text { i) Design, develop, implement, and test the planned socialification } \\
\text { elements. }\end{array}$ & $\begin{array}{l}\text { reach this level of integration. Those are the focus } \\
\text { of the later weeks }(9,10,11,12 \text {, and 13) }\end{array}$ \\
\hline
\end{tabular}




\section{Current State and Challenges}

Designing interdisciplinary courses which include a technical, social, and business component requires specific planning and consideration [34]. For example, both technical and non-technical students may be interested. However, disciplines may vary in their will to offer the course. As the course approval process unfolds, traditionally separate departments, possibly in different faculties, may need to collaborate to implement the course.

Ensuring students have sufficient background to succeed in interdisciplinary courses also poses challenges in the student recruitment and retention for the course. However, we suggest that these factors would be balanced by the interest level in this timely topic. In this respect, a challenge maybe ensuring timely implementation of this course given course validation and planning processes at the university undergraduate level.

The lack of course materials that are targeted to undergraduate level of this course may pose another challenge. Currently, there are no textbooks available for this topic. We suggest the use of handouts, video lectures, and journal articles from the practitioner and research literatures. We suggest professors supply these learning materials in as many formats as possible to accommodate all learning styles [47]. The details for each cited article in the learning materials and reading list is included in the References section.

The next steps which will be needed in furthering the development and diffusion of this course are focused on learning and teaching materials. The following would be needed for successful implementation of this course:

Develop learning materials (textual or other media formats such as videos) to help support student learning. The focus would be on integrating knowledge into a text book level set of materials as opposed to the currently available collections of academic papers.

Develop teaching notes and tools to support instructors' delivery of active learning experiences. These would be in conjunction with the learning materials but will also include additional tools such as suggested active learning activities for in-class, virtual, flipped, and peer focused learning.

Develop learning assessment guides for both graded and non-graded learning activities.

Develop evaluation rubrics to serve as standardization and communication devices between instructors and students.

Develop study guides to assist students in knowing and revising the most important learning materials.

\section{Summary}

This paper has discussed the need for a course on social software element analysis, design, and implementation. We hope to initiate a conversation on this domain of knowledge to discuss the transfer of the accumulating knowledge to the next generation of software engineers. We articulate a set of course goals, learning objectives, and discuss the structure of the course which is suggested to support these goals and objectives. Finally, we discuss challenges and invite colleagues to reflect and discuss with us the following: Should the course include integration techniques in the readings, lectures, workshops with students? Student assessment: Are exams needed or would a portfolio of artifacts with a contribution articulation-based approach be appropriate? What's the role of peer feedback in such a course and how should it be treated? What are the best avenues to legitimize and diffuse the course, including maximizing enrollment?

\section{References}

[1] Addas, S., and A. Pinsonneault, "The many faces of information technology interruptions: a taxonomy and preliminary investigation of their performance effects", Information Systems Journal 25(3), 2015, pp. 231-273.

[2] Ayouby, R., and A.-M. Croteau, "Problematic Social Media Use and Implicit Motives", Proceedings of the Administrative Sciences Association of Canada, ASAC (2015).

[3] Ayouby, R., and A.-M. Croteau, "Cognitive Foreshadowing HICSS 2016 Symposium Presentation-How do the implicit affiliation and implicit achievement motives influence problematic social media use?", 2016.

[4] Ayouby, R., and A.-M. Croteau, "Social Media Use viewed through an Integration of Motive Disposition Theory and Attachment Theory", 2017.

[5] Beck, S.J., A.L. Meinecke, Y. Matsuyama, and C.-C. Lee, "Initiating and Maintaining Collaborations and Facilitating Understanding in Interdisciplinary Group Research", Small Group Research 48(5), 2017, pp. 532-543.

[6] Brambilla, M., J. Cabot, and M. Wimmer, "ModelDriven Software Engineering in Practice, Second Edition", Synthesis Lectures on Software Engineering 3(1), 2017, pp. $1-207$.

[7] vom Brocke, J., Bernard C.Y. Tan, Heikki Topi, and Markus Weinmann, AIS Global IS Education Report, AIS, EDUglopedia.org, 2017.

[8] Buchgeher, G., M. Winterer, R. Weinreich, J. Luger, R. Wingelhofer, and M. Aistleitner, "Microservices in a Small Development Organization", In A. Lopes and R. de Lemos, eds., Software Architecture. Springer International Publishing, Cham, 2017, 208-215. 
[9] Cadwalladr, C., “'I made Steve Bannon's psychological warfare tool': meet the data war whistleblower", The Guardian, 2018. http://www.theguardian.com/news/2018/mar/17/data-warwhistleblower-christopher-wylie-faceook-nix-bannontrump

[10] Cheikh-Ammar, M., and H. Barki, "The Influence of Social Presence, Social Exchange and Feedback Features on SNS Continuous Use:: The Facebook Context", Journal of Organizational and End User Computing 28(2), 2016, pp. 33-52.

[11] Douglas Harper, "Online Etymology Dictionary", www.dictionary.com, 2010. https://www.dictionary.com/browse/social

[12] European Union, General Data Protection Regulation, 2016.

[13] Expedia Group Executive, "Personal communication", 2018.

[14] Facebook, "Facebook Newsroom", Facebook News Room, 2018. https://newsroom.fb.com/company-info/

[15] Freshworks Inc., "Freshchat", https://www.freshworks.com/content/en-US/live-chatsoftware/

[16] Gagné, M., "From Strategy to Action: Transforming Organizational Goals into Organizational Behavior", International Journal of Management Reviews 20, 2018, pp. S83-S104.

[17] Gagné, M., and E.L. Deci, "Self-determination theory and work motivation", Journal of Organizational behavior 26(4), 2005, pp. 331-362.

[18] Gans, J., Enhancing competition with data and identity portability, Brookings Institutue, 2018.

[19] Gillespie, T., "The politics of "platforms"”, New Media \& Society 12(3), 2010, pp. 347-364.

[20] Guzdial, M., and S. Landau, "Programming Programming Languages, and Analyzing Facebook's Failure", Communications of the ACM 61(6), 2018, pp. 8-9.

[21] Haselböck, S., R. Weinreich, and G. Buchgeher, "Decision Models for Microservices: Design Areas, Stakeholders, Use Cases, and Requirements", In A. Lopes and R. de Lemos, eds., Software Architecture. Springer International Publishing, Cham, 2017, 155-170.

[22] Herzog, C., A. Richter, and M. Steinhüser, "Towards a framework for the evaluation design of enterprise social software", 2015.

[23] Isaak, J., and M.J. Hanna, "User Data Privacy: Facebook, Cambridge Analytica, and Privacy Protection", Computer 51(8), 2018, pp. 56-59.

[24] Ju, W., "The design of implicit interactions", Synthesis Lectures on Human-Centered Informatics 8(2), 2015, pp. 193.
[25] Kane, G.C., "The evolutionary implications of social media for organizational knowledge management", Information and Organization, 2017.

[26] Kane, G.C., M. Alavi, G. (Joe) Labianca, and S.P. Borgatti, "What's Different About Social Media Networks? a Framework and Research Agenda", MIS Quarterly 38(1), 2014, pp. 275-304.

[27] Kaplan, A.M., and M. Haenlein, "Users of the world, unite! The challenges and opportunities of Social Media", Business Horizons 53(1), 2010, pp. 59-68.

[28] Karahanna, E., S. Xin Xu, Y. Xu, and N. (Andy) Zhang, "The Needs-Affordances-Features (NAF) Perspective for the Use of Social Media", MIS Quarterly (Forthcoming) Forthcoming,

[29] Kassner, L., P. Hirmer, M. Wieland, F. Steimle, J. Königsberger, and B. Mitschang, "The Social Factory: Connecting People, Machines and Data in Manufacturing for Context-Aware Exception Escalation", Hawaii International Conference on System Sciences 2017 (HICSS50), 2017.

[30] Kietzmann, J.H., K. Hermkens, I.P. McCarthy, and B.S. Silvestre, "Social media? Get serious! Understanding the functional building blocks of social media", Business Horizons 54(3), 2011, pp. 241-251.

[31] Kietzmann, J.H., B.S. Silvestre, I.P. McCarthy, and L.F. Pitt, "Unpacking the social media phenomenon: towards a research agenda", Journal of Public Affairs 12(2), 2012, pp. 109-119.

[32] Klein, J.T., and W.H. Newell, "Advancing interdisciplinary studies", In J. Gaff and J. Ratcliff, eds., Handbook of the undergraduate curriculum: A comprehensive guide to purposes, structures, practices, and change. Jossey-Bass, San Franciso, CA, 1997, 393-415.

[33] Klemmer, S., "Social Computing", Coursera. https://www.coursera.org/learn/social-computing

[34] Lago, P., J. Schalken, and H. van Vliet, "Designing a multi-disciplinary software engineering project", Software Engineering Education and Training, 2009. CSEET'09. 22nd Conference on, IEEE (2009), 77-84.

[35] Lattuca, L., and D. Knight, "In the eye of the beholder: Defining and studying interdisciplinarity in engineering education", American Society for Engineering Education, American Society for Engineering Education (2010).

[36] Lattuca, L.R., D. Knight, and I. Bergom, "Developing a Measure of Interdisciplinary Competence", International Journal of Engineering Education 29(3), 2013, pp. 726-739.

[37] Lattuca, L.R., D.B. Knight, H.K. Ro, and B.J. Novoselich, "Supporting the Development of Engineers' Interdisciplinary Competence", Journal of Engineering Education 106(1), 2017, pp. 71-97.

[38] Leonardi, P.M., "When Flexible Routines Meet Flexible Technologies: Affordance, Constraint, and the Imbrication of Human and Material Agencies", MIS Quarterly 35(1), 2011, pp. 147-168. 
[39] Leonardi, P.M., “Ambient Awareness and Knowledge Acquisition: Using Social Media to Learn 'Who Knows What' and 'Who Knows Whom", MIS Quarterly 39(4), 2015, pp. 747-762.

[40] Leonardi, P.M., M. Huysman, and C. Steinfield, "Enterprise Social Media: Definition, History, and Prospects for the Study of Social Technologies in Organizations", Journal of Computer-Mediated Communication 19(1), 2013, pp. 1-19.

[41] Leonardi, P.M., and E. Vaast, Social Media and Their Affordances for Organizing: A Review and Agenda for Research, Social Science Research Network, Rochester, NY, 2017.

[42] Leoz, G.D., and S. Petter, "Considering the social impacts of artefacts in information systems design science research", European Journal of Information Systems 27(2), 2018, pp. 154-170.

[43] Lewis, P., “'Utterly horrifying': ex-Facebook insider says covert data harvesting was routine", The Guardian, 2018.

http://www.theguardian.com/news/2018/mar/20/facebookdata-cambridge-analytica-sandy-parakilas

[44] Loop 11, The 2018 UX Industry Report, Loop11.com, 2018.

[45] Maffei, L., "Expedia acquires travel photography community Trover", TechCrunch, 2016. http://social.techcrunch.com/2016/07/20/expedia-acquirestrover/

[46] Mahara, "Home - Mahara ePortfolio System", 2018. https://mahara.org/

[47] National Center On Universal Design for Learning, at CAST, "UDL Guidelines 2.0 | National Center On Universal Design for Learning", http://www.udlcenter.org/aboutudl/udlguidelines

[48] Newell, W.H., "13 Decision Making in Interdisciplinary Studies", In G. Morcol, ed., Handbook of Decision Making. CRC Press/Taylor \& Francis Group, 2007.

[49] Newman, P., M.A. Ferrario, W. Simm, S. Forshaw, A. Friday, and J. Whittle, "The role of design thinking and physical prototyping in social software engineering", Proceedings of the 37th International Conference on Software Engineering-Volume 2, IEEE Press (2015), 487496.

[50] Oettl, C., T. Berger, M. Böhm, M. Wiesche, and H. Krcmar, "Archetypes of Enterprise Social Network Users", Proceedings of the 51st Hawaii International Conference on System Sciences, (2018).

[51] Rapp, A., F. Cena, C. Gena, A. Marcengo, and L. Console, "Using game mechanics for field evaluation of prototype social applications: a novel methodology", Behaviour \& Information Technology 35(3), 2016, pp. 184195.

[52] Reuters, "Facebook Now Has an Almost AdvertisingOnly Business Model”, Fortune, 2017. http://fortune.com/2017/05/05/facebook-digital-advertisingbusiness-model/

[53] Schriek, C., J.M.E.M. van der Werf, A. Tang, and F. Bex, "Software Architecture Design Reasoning: A Card Game to Help Novice Designers", In B. Tekinerdogan, U. Zdun and A. Babar, eds., Software Architecture. Springer International Publishing, Cham, 2016, 22-38.

[54] Schultheiss, O.C., "Implicit motives", In O.P. John, R.W. Robins and L.A. Pervin, eds., Handbook of personality: Theory and research (3rd ed.). Guilford Press, New York, NY, US, 2008, 603-633.

[55] Seethamraju, R., "Adoption of Software as a Service (SaaS) Enterprise Resource Planning (ERP) Systems in Small and Medium Sized Enterprises (SMEs)", Information Systems Frontiers 17(3), 2015, pp. 475-492.

[56] Seffah, A., and P. Forbrig, Patterns of HCI design and HCI design of patterns: bridging HCI design and modeldriven software engineering, Springer, Cham, 2015.

[57] Sharaf, M., M. Abughazala, H. Muccini, and M. Abusair, "An Architecture Framework for Modelling and Simulation of Situational-Aware Cyber-Physical Systems", In A. Lopes and R. de Lemos, eds., Software Architecture. Springer International Publishing, Cham, 2017, 95-111.

[58] Tarhini, A., H. Ammar, and T. Tarhini, "Analysis of the critical success factors for enterprise resource planning implementation from stakeholders' perspective: A systematic review", International Business Research 8(4), 2015 , pp. 25 .

[59] Turel, O., and H. Qahri-Saremi, "Problematic Use of Social Networking Sites: Antecedents and Consequence from a Dual System Theory Perspective", Journal of Management Information Systems, 2017.

[60] University of Michigan School of Information, "Developing Social Computing", University of Michigan School of Information, 2017. https://www.si.umich.edu/programs/master-scienceinformation/developing-social-computing

[61] Wikimedia, “-ification definition”, Wiktionary, 2018. https://en.wiktionary.org/wiki/-ification

[62] Yang, C., P. Liang, P. Avgeriou, U. Eliasson, R. Heldal, and P. Pelliccione, "Architectural Assumptions and Their Management in Industry - An Exploratory Study", In A. Lopes and R. de Lemos, eds., Software Architecture. Springer International Publishing, Cham, 2017, 191-207.

[63] Zhao, Y., J. Liu, J. Tang, and Q. Zhu, "Conceptualizing perceived affordances in social media interaction design", Aslib Proceedings 65(3), 2013, pp. 289-303.

[64] "ALICE", Company. aliceplatform.com 